\title{
A queixa escolar: Reflexões sobre o atendimento psicológico
}

\author{
School complaint: Reflections on the psychological care
}

\author{
Danilly Rafaelly Martins Cruz ${ }^{[a]}$, Lucivanda Cavalcante Borges ${ }^{[b]}$
}

\footnotetext{
${ }^{\text {[a] }}$ Psicóloga pela Universidade Federal do Vale do São Francisco (Univasf), Petrolina, PE - Brasil, e-mail: danillycruz@hotmail.com

${ }^{[b]}$ Mestre em Psicologia Social pela Universidade Federal da Paraíba (UFPB), professora assistente da Universidade Federal do Vale do São Francisco (Univasf), Petrolina, PE - Brasil, e-mail: luci.cborges@ig.com.br
}

Recebido: 01/01/2012 Received: 01/01/2012

Aprovado: 27/03/2012 Approved: 03/27/2012

\section{Resumo}

Historicamente, a atuação do psicólogo na escola é caracterizada por uma prática diagnóstica, em que são utilizados testes ou laudos com o objetivo de identificar os principais aspectos relacionados ao fracasso escolar e, consequentemente, emitir um parecer sobre os alunos avaliados. Consequentemente, na maioria dos casos, os alunos ou seus familiares eram considerados os únicos responsáveis pelo não aprendizado e passavam a vivenciar a exclusão. Este estudo teve como objetivo conhecer o modelo de atuação dos psicólogos que atendem crianças com dificuldades no processo de escolarização. Foi realizada uma pesquisa qualitativa, com um roteiro semiestruturado e o uso de um gravador. Foram entrevistados oito sujeitos, de instituições públicas de Petrolina (PE), sendo seis psicólogos e dois estagiários de Psicologia. Constatou-se que a maioria dos profissionais realiza uma avaliação breve da criança e a encaminha para exames e consultas médicas, ou emitem laudos psicológicos. Boa parte dos sujeitos relatou não realizar qualquer tipo de intervenção nesses casos, e quando necessário, realizam apenas psicoterapia.

Palavras-chave: Educação. Psicologia escolar. Aprendizagem. Atuação profissional.

\section{Abstract}

Historically, the school psychologist's performance is characterized by a diagnostic practice, which tests or reports are used, these in order to identify key issues related to school failure, and thus give an opinion on the students evaluated. Consequently, in most cases, students or their families were considered solely responsible for learning and not passed to experience exclusion. This study aimed to assess the performance of psychologists who treat children with difficulties in the process of schooling, in public institutions of Petrolina (PE - Brazil). We conducted a qualitative study, with a semi-structured script and use of a recorder. Eight people were interviewed in public institutions, six psychologists and two psychology interns. It was found that most professionals conduct a brief assessment of the child and afterwards they issue psychological reports or lead to medical examinations and consultations. Most of the subjects reported not taking any kind of intervention, in these cases, when is necessary, they only accomplish individual or group psychotherapy.

Keywords: Education. Educational psychology. Learning. Professional practice. 


\section{Introdução}

O discurso sobre o fracasso escolar esteve inúmeras vezes relacionado a fatores extraescolares, como características do aluno e problemas familiares. A partir da década de 70, esse problema se deslocou da esfera biológica para a cultural, na qual principalmente crianças de baixa renda, consideradas como alunos com defasagem sociocultural, eram "culpadas" por não conseguirem adquirir os conhecimentos que lhes eram transmitidos (Molina \& Del Prette, 2006). Essa concepção decorre da teoria da carência cultural, muito criticada por diferentes autores (Braga \& Morais, 2007; Patto, 1990; Sawaya, 2000).

Vários fatores podem ser abordados na análise desse problema, porém as reais causas necessitam de reavaliação, com base no conhecimento dos mecanismos escolares produtores de dificuldades de aprendizagem.

A metodologia utilizada pelo educador pode ser fator predominante, já que modelos adequados de aprendizagem de um aluno ideal não encontram correspondência na realidade, e isso se deve não apenas às diferenças culturais, mas recai sobre a inadequação da escola, visto que ela deveria contemplar diferentes técnicas e métodos, com o intuito de incluir os alunos no processo de ensino-aprendizagem (Patto, 1997).

Historicamente, a atuação do psicólogo na escola é caracterizada por uma prática diagnóstica, com testes ou laudos visando identificar os principais aspectos relacionados ao fracasso escolar e, consequentemente, emitir um parecer sobre os alunos avaliados. Consequentemente, na maioria dos casos, os alunos ou seus familiares eram considerados os únicos responsáveis pelo não aprendizado e passavam a vivenciar a exclusão (Andrada, 2005).

Segundo Azevedo (2000), essa prática psicológica distorcida decorre da demanda e expectativas das escolas. Estas buscam um atendimento individualizado, direcionado apenas ao aluno, no intuito de solucionar um maior número de "problemas". 0 psicólogo deixa de compreender as relações constituídas no espaço escolar e não desempenha a ação de escutar os atores envolvidos, incorrendo no erro de atribuir ao próprio aluno e à família a responsabilidade pelo insucesso escolar (Nakamura, Lima, Tada \& Junqueira, 2008).
Inúmeras pesquisas sobre o atendimento psicológico a escolares na rede pública de saúde e em clínicas-escolas apontam que a grande demanda por esse tipo de atendimento decorre da inadaptação do aluno e das dificuldades de aprendizagem (Braga \& Morais, 2007; Cabral \& Sawaia, 2001).

Conforme Braga e Morais (2007), embora tais estudos apontem para a necessidade de investigar questões que vão além da dinâmica individual e familiar, ainda é fator presente na atuação dos profissionais a culpabilização dos alunos, quando atribui origem biológica ou psicológica a esses comportamentos.

Os encaminhamentos das crianças que supostamente apresentam dificuldades de aprendizagem chegam aos profissionais ligados às escolas, Unidades Básicas de Saúde (UBS) e outros locais que oferecem atendimentos psicológicos (Souza, 2007). Embora exista esse tipo de atendimento na maioria desses locais, é notório o despreparo de alguns psicólogos diante dessa demanda específica. Assim, para Dimenstein, uma parte deles assume o modelo clínico liberal privatista em suas práticas (Braga \& Morais, 2007).

Esse modelo consiste numa prática ligada ao atendimento individual e uma intervenção, biológica ou psicológica, que confere muito tempo e pouca efetividade, visto que não integra a escola e a família nesse processo.

Consequentemente, uma parte desses profissionais realiza atendimento e tratamento baseados em moldes ou teorias, padronizados, estudados durante a formação. Logo, desconsideram a singularidade de cada processo de aprendizagem e não desenvolvem uma intervenção que ultrapasse o espaço de atendimento. Assim, o psicólogo não intervém nas singularidades, tampouco estabelece o diálogo entre os atores envolvidos - que seria uma das formas de criar propostas de enfrentamento das dificuldades apresentadas pelas crianças.

Ao investigar e intervir na queixa escolar, é necessário considerar aspectos sociais, políticos e institucionais, além de compreender o ambiente cultural em que a criança está inserida e conhecer as relações estabelecidas no contexto escolar. Desse modo, alguns autores propõem uma nova forma de atendimento à queixa escolar que abandona o foco no indivíduo, ultrapassa o consultório e os muros escolares (Braunstein, 2010). 


\section{0 psicólogo escolar/educacional diante dessa demanda}

A inserção do psicólogo nas escolas traz benefícios para a construção de uma nova identidade profissional, antes baseada no atendimento individualizado de "alunos-problemas". A regulamentação da profissão, no âmbito da educação, aborda a possibilidade de pesquisas, diagnósticos e intervenções em todos os segmentos do sistema educacional que participam do processo de ensino-aprendizagem (Andrada, 2005).

Em boa parte de suas atuações, o psicólogo educacional se depara com a demanda da escola por laudos e diagnósticos, na expectativa de solucionar problemas de inadequação e dificuldades de aprendizagem. Esse fato representa o quanto algumas escolas estão à margem das discussões sobre aprendizagem, incorrendo na prática de encaminhar as crianças "indesejadas" aos diferentes tipos de atendimento em saúde.

Esse encaminhamento acarreta uma série de agravantes, visto que os profissionais de saúde e educação ainda apresentam a visão pautada no paradigma normalidade versus anormalidade, no qual se espera um padrão de comportamento "ideal" para que exista o sucesso escolar (Andrada, 2005).

Desse modo, a medicalização passa a ser frequente, tanto quanto a busca por uma causa para tais comportamentos, e assim, como afirmam Collares e Moysés (1994), as questões de origem social e política tentam encontrar, no campo médico, causa e solução para seus problemas. Partindo desse pressuposto, a aprendizagem e a dificuldade de aprendizagem são apontadas como algo individual, isentando o professor de qualquer responsabilidade no processo destacado, o que implica em um erro grave e frequente.

Esse equívoco se reflete nos diagnósticos de fracasso entre alunos matriculados na $1^{\underline{a}}$ série da rede pública de ensino, em que os alunos apresentam algum problema de origem psicológica, biológica ou familiar, enquanto, segundo Santos, a instituição escolar e o sistema educacional são raramente descritos como causadores de tais "problemas" (Braga \& Morais, 2007).

Boa parte dos pesquisadores, tais como Patto (1990), Braga e Morais (2007), Machado e Souza (1997), enfatiza as reais razões da grande quantidade de crianças que "não aprendem" ou não se adequam aos métodos educacionais utilizados.
Pesquisas demonstram a produção do fenômeno chamado fracasso escolar, instaurado e sem perspectivas de mudança.

O psicólogo passa a ponderar alguns aspectos, e logo o questionamento frequente se define em: receber, ou não, casos ligados ao tema enfatizado acima? Em boa parte das oportunidades, o profissional o aceita e realiza uma investigação centrada na criança para remover o "suposto" obstáculo que a impede de aprender e corresponder ao padrão de comportamento estabelecido.

De acordo com Santos (2002), a análise individualizada é fundamental, contudo outros fatores são relevantes, como o histórico escolar da criança, suas experiências anteriores ao processo de escolarização, sua opinião sobre a queixa, a posição da escola, dentre outras formas de investigação e avaliação baseadas no contexto em que o discente se insere, de modo a fornecer uma prática sem a reprodução mecânica de técnicas e procedimentos.

Ainda segundo esse autor (2002), o ato educativo é ainda um processo homogeneizado, do qual se exclui a singularidade. A atuação do psicólogo deve ser pensada com objetivos terapêuticos, com intervenções nas relações, nos discursos e nas práticas cotidianas das escolas. Assim, os problemas de aprendizagem podem ser identificados na origem do processo, com o intuito de contribuir na transformação do cenário social.

Embora a importância do psicólogo seja destacada, alguns fatores contribuem para o afastamento desses profissionais do campo da educação. Aspectos como número reduzido de escolas que buscam tais profissionais, além das dificuldades de articulação dos profissionais da rede pública de saúde com as escolas, são pontos negativos enfatizados.

Com o objetivo de estreitar as relações, existem políticas públicas de saúde que visam à articulação desses espaços, porém na prática tais ações "esbarram" na falta de recursos humanos e na incompreensão de gestores e chefias. Surge a necessidade de uma reorientação na formação profissional, buscando fomentar a atuação dos psicólogos na área educacional.

Nesse contexto, o presente trabalho teve como objetivo conhecer a atuação dos psicólogos que atuam em instituições públicas de Petrolina (PE), diante da demanda por atendimentos a escolares com supostos problemas ou dificuldades de aprendizagem. 
A relevância deste estudo incide em fundamentar a necessidade de ações articuladas entre serviços de atenção à saúde e a instituições de ensino, já que boa parte desses encaminhamentos não se refere aos problemas de aprendizagem e poderiam ser solucionados na própria escola, com família e professores. Ademais, considera-se necessária a realização de mudanças nos espaços educativos e sociais que perpetuam ações que não levam em conta as diferenças na aprendizagem dos alunos, promovendo a psicologização e a medicalização nas escolas.

\section{Participantes}

Esta pesquisa foi realizada com oito sujeitos atuantes em instituições públicas de saúde, educação e assistência social na cidade de Petrolina (PE). Nesses locais, foram entrevistados seis profissionais e dois estagiários de psicologia. Estes foram incluídos na pesquisa, pois realizam atendimentos nos locais visitados durante o processo de coleta de dados. Os critérios para seleção foram: realizar atendimentos a crianças ou adolescentes em idade escolar, aceitar participar do estudo e dispor-se a receber os pesquisadores.

\section{Instrumento}

Foi utilizado, como instrumento, um roteiro de entrevista semiestruturada. As entrevistas foram realizadas no local de trabalho, individualmente.

\section{Análise dos dados}

A partir do material transcrito, fez-se o desdobramento de todas as falas em temas ou unidades de significação, visando atingir uma representação do conteúdo e de sua expressão, o que possibilitou a organização do material coletado em temas: "causas das dificuldades de aprendizagem", "atuação dos psicólogos", "contato com os pais da criança", "contato com a escola ou professor da criança" e "como avalia seu trabalho, em relação a esse tipo de demanda". Essas unidades temáticas foram analisadas qualitativamente com base em seu referencial bibliográfico.

\section{Resultados e discussões}

Os sujeitos que participaram desse estudo constituem uma população de adultos jovens, com o predomínio do sexo feminino. Tendo em vista o número reduzido de psicólogos entrevistados, foram garantidos sigilo e anonimato, sem relacionar o sujeito ao seu respectivo local de trabalho.

De maneira geral, percebe-se uma considerável demanda de atendimentos a crianças e adolescentes com queixa de dificuldades de aprendizagem nesses locais. As instituições chegam a receber de um a cinco casos por dia. Alguns encaminhamentos são feitos por escolas, e outros caracterizam uma demanda espontânea da família.

Os psicólogos entrevistados têm formação em Psicologia, mas apenas um possui especialização para atender crianças com dificuldades de aprendizagem. Em relação aos atendimentos que realizam, seis dos participantes afirmam atender crianças, jovens e idosos, e os outros dois participantes atendem apenas crianças e seus pais. Ainda sobre a demanda das crianças e adolescentes, prevalecem os atendimentos aos do sexo masculino, de diferentes escolas públicas e de bairros periféricos. "A maioria é de meninos, entre 5 e 8 anos... e... a maioria vem dos projetos dos bairros periféricos..." (Sujeito 1). "Todos do sexo masculino, entre 6 e 17 anos... eles vêm de diferentes escolas públicas, aqui do bairro mesmo..." (Sujeito 2).

Segundo pesquisas realizadas no Brasil, a questão de gênero é algo presente na educação, esses dados apontam um fracasso escolar maior entre os meninos. A análise dessa realidade vai desde a questão cultural da masculinidade até outros questionamentos estereotipados da passividade feminina. Assim, essa discussão é também necessária no campo da educação, visto que deve ser priorizada a igualdade e a democracia (Carvalho, 2003).

Boa parte desses encaminhamentos vem das escolas e se refere a dificuldades de aprendizagem, comportamentos agressivos, problemas familiares, falta de interesse do próprio aluno e metodologia do professor em sala. Sobre esses encaminhamentos, a maioria dos pais desconhece os motivos da queixa e levam os filhos para o atendimento psicológico sem ter uma conversa com a escola ou o professor que o encaminhou ao profissional. Podemos perceber isso na seguinte afirmação: 
... Os pais chegam aqui sem saber os motivos do encaminhamento, e muitas coisas podem ser resolvidas na própria escola, como é o caso da falta de limites, que é uma coisa que vem da família e acaba prejudicando a escola... (Sujeito 4).

Tais dados corroboram aqueles encontrados em pesquisas como as de Braga e Morais (2007) e Souza (2007).

\section{Causas das dificuldades de aprendizagem}

Nesta unidade temática, foram consideradas as dificuldades de aprendizagem como fatores de ordem biopsicossocial, que influenciam na escolarização das crianças. Essas dificuldades decorrem de diferentes causas, incluindo as relações sociais, a metodologia de ensino abordada na escola e questões biológicas e subjetivas da própria criança.

Aspectos como nível de renda familiar e escolaridade, situação social, falta de informação, desinteresse por parte de pais e responsáveis, além de problemas de caráter familiar, foram pontos abordados pelos sujeitos da pesquisa no intuito de justificar as possíveis causas para as dificuldades de aprendizagem identificadas nos diversos atendimentos realizados. Alguns trechos das entrevistas apresentam esses fatores: "A condição socioeconômica e a falta de informação dos pais, o nível de escolaridade dos pais..." (Sujeito 2). "Acredito que a maioria dessas dificuldades se deve às condições socioeconômicas e o nível de escolaridade dos pais... a maioria tem pais analfabetos e as crianças não tem perspectivas, interesse... ou objetivos na vida..." (Sujeito 5).

Segundo a literatura enfatizada nesse trabalho (Braga \& Morais, 2007; Patto, 1990; Sawaya, 2000), percebe-se que essas afirmações são decorrentes de uma visão pautada na teoria de carência cultural, segundo a qual a falta de instrução dos pais e as condições socioeconômicas são apontadas como a causa das dificuldades das crianças.

Apenas um dos entrevistados relata a instituição escolar como responsável pelas dificuldades demonstradas pelas crianças, conforme trecho a seguir: "Acho que a escola é a principal responsável por essas dificuldades, quando não oferece uma educação de qualidade... alguns professores acabam encaminhando a maioria dos seus alunos e não percebem que existe algo errado nisso..." (Sujeito 4).
Essa afirmação propõe que a escola também necessita modificar suas ações, no sentido de perceber sua metodologia e ações diante dos alunos, visto que encaminhar para atendimento a maioria de seus alunos pode representar uma necessidade de reformulação de sua própria conduta educativa.

No entanto, esses encaminhamentos são constantes nos diferentes locais e isso preconiza o olhar faltoso, sendo o aluno culpado pela "não aprendizagem". Entende-se que lhe falta algo e, por isso, deve-se investigar a causa do seu problema, cuja origem pode ser biológica, psicológica ou social. Desse modo, essa demanda cresce desordenada e é uma das principais na maioria dos locais visitados.

As respostas obtidas assemelham-se aos resultados encontrados nas pesquisas citadas neste trabalho, como a de Braga e Morais (2007) e Souza (2007), quando afirmam a existência de uma visão reducionista dos profissionais sobre as causas das dificuldades de aprendizagem. A maioria deles aponta o aluno, a família ou a condição socioeconômica como principais causas para o "fracasso escolar" das crianças, tornando isenta a instituição escolar nesse processo.

\section{Atuação dos psicólogos}

Nesse aspecto, buscou-se considerar as diferenças dos locais visitados: instituições de saúde, educação e assistência social. Isso porque elas são regidas por uma política institucional que deve ser incorporada em cada tipo de procedimento adotado, porém, demonstraram semelhanças no atendimento dessa demanda.

Em relação à atuação dos psicólogos, todos recebem determinada queixa da escola ou da família, e realizam uma avaliação baseada em uma conversa com os pais e com a criança, ou seguem um roteiro de anamnese preestabelecido, que pouco cumpre o objetivo de traçar um perfil do sujeito. Essa avaliação ocorre em apenas um encontro e nenhum dos entrevistados utiliza testes psicométricos. Em seguida, são transmitidas orientações aos pais, são emitidos laudos sobre as crianças, ou são realizados encaminhamentos para exames, consultas médicas ou psicoterapia.

Os trechos abaixo apresentam alguns pontos que compõem grande parte do processo de atendimento: 
Primeiro, as crianças passam por uma avaliação psicopedagógica, com as psicopedagogas, e só depois elas chegam a mim, só algumas quando têm algum trauma ou problema emocional, algum bloqueio ou deficiência... Faço primeiro uma anamnese com os pais, bem detalhada, para investigar a causa das dificuldades de aprendizagem da criança... Depois, eu converso com a criança, coloco alguns brinquedos na mesa para ela se expressar... (Sujeito 4).

Procuro investigar como foi a vida dessa criança desde seu nascimento, a entrada na escola, se foi uma gravidez desejada, uma anamnese mesmo. Depois faço alguns testes, que vou criando na hora, de escrever palavras, desenhar... E sempre oriento os pais (Sujeito 6).

A partir disso, podemos inferir que a anamnese é utilizada pelos profissionais que buscam investigar a história de vida da criança. 0 primeiro trecho aborda uma atuação em equipes onde essa triagem inicial é realizada por outros profissionais, e somente alguns casos são direcionados para atendimento psicológico. Já no segundo trecho, podemos perceber no psicólogo uma tentativa de buscar as causas das dificuldades de aprendizagem através da anamnese, assim como na observação de atividades direcionadas. "Aqui a gente não faz psicoterapia, então a gente escuta e encaminha para a policlínica, para psicólogos, ou para fazer consultas médicas ou exames" (Sujeito 6).

Nosso primeiro papel é fazer a escuta, nesse primeiro momento, e quando o problema é identificado, a gente entra mais com um papel mais psicoterápico mesmo. Aí ele é inserido nos grupos, nas atividades que nós temos aqui, que vão auxiliar, né? (Sujeito 8).

Nesses relatos, podemos identificar uma atuação mais direcionada ao método psicoterápico. Embora o segundo entrevistado demonstre não realizar esse tipo de intervenção, em sua fala deixa claro que essa seria sua forma de atuação nesses casos. Além disso, podemos identificar que existe um (re)encaminhamento das crianças para a policlínica ou para exames e consultas médicas.

Em relação a isso, é importante que o profissional psicólogo tenha mais cuidado na investigação dos problemas de aprendizagem, visto que pouco se sabe sobre essa queixa e, com base em relatos da criança e dos pais, são emitidos pareceres, laudos e encaminhamentos. Podemos, então, perceber uma mudança na atuação do psicólogo, que começa a assemelhar-se à postura médica, contemplando maior resolutividade e um discurso genérico aplicado sem que o contexto e as inserções sociais sejam considerados (Saraiva, 2007).

No entanto, devem ser incorporados nessa atuação mais elementos, desde um atendimento mais prolongado a uma análise mais ampliada, que contemple mais informações e técnicas, pois a queixa apresentada como dificuldade de aprendizagem pode ter outra origem ou ser solucionada com mudanças simples.

A partir desses relatos, podemos inferir a dificuldade de profissionais que realizam algum tipo de intervenção voltada para essa demanda na rede pública da cidade, o que gera encaminhamentos desnecessários para área da saúde, mesmo sem ter sido realizada uma investigação detalhada, na perspectiva multifatorial dos problemas de aprendizagem.

\section{Contato com os pais da criança}

Todos os entrevistados oferecem acolhimento aos pais ou responsáveis, explicam a queixa e realizam orientações, abordando aspectos observados durante $\mathrm{o}$ atendimento à criança, conforme afirmações apresentadas a seguir: "Sempre realizo o atendimento e depois dou um feedback aos pais" (Sujeito 6).

Aqui o trabalho é feito em equipe, depois nós sentamos e conversamos sobre os casos para chegar a uma conclusão sobre esses eles e aconselhar os pais... Nosso objetivo é avaliar e orientar, o atendimento é breve... Se for um caso que necessite psicoterapia, eu encaminho para outro psicólogo (Sujeito 4).

Os entrevistados também apontam a ansiedade em solucionar o "problema" do filho como fator predominante nesses pais. Eles insistem em receber algum tipo de retorno desses profissionais (encaminhamento ou orientação), enquanto os entrevistados demonstram não saber lidar com essa situação, quando fornecem orientações e diagnósticos precoces.

Essa ansiedade que envolve os pais acerca do desempenho escolar dos filhos é uma das causas 
da busca pelos atendimentos psicológicos nesses locais. Desse modo, isso deve ser tratado com cuidado, pois muitas vezes essa ansiedade de desempenho pode gerar uma pressão exaustiva sobre a criança. Da mesma forma, o diagnóstico conferido pode representar uma mudança grande na forma como ela é vista e tratada pelos familiares.

Assim, também é necessário que exista o estabelecimento de um diálogo mais prolongado com esses pais, a fim de conhecer realmente essa demanda e poder traçar estratégias capazes de contribuir para que as relações familiares intervenham positivamente na vida da criança e em sua educação.

\section{Contato com a escola ou professor da criança}

Nessa investigação, foram considerados os contatos com a escola, como uma conversa com algum representante escolar ou uma comunicação escrita, visando discutir o caso ou fornecer algum tipo de orientação sobre a aprendizagem da criança ou do adolescente.

Assim, seis dos psicólogos garantem realizar esse tipo de contato, apenas quando existe a necessidade, mas, logo em seguida, afirmam que em boa parte dos casos não é necessário. Algumas afirmações como "... Quando necessário... mas, até agora não teve necessidade" e "Não, nunca realizei" reforçam a ideia anterior.

Apenas dois entrevistados reconhecem a necessidade do contato com a escola, e esse diálogo é realizado por outros profissionais, com o objetivo de agregar dados para a "solução do problema", não promovendo o diálogo entre a escola, a família e o aluno, que segundo Andrada (2005), seria fundamental para o desenvolvimento de ações conjuntas, para promover a aprendizagem do aluno:

A equipe vai à escola ouvir e conversar com os professores. Porque tem muitos casos de discriminação, por isso é importante orientar a escola. Nós tentamos ouvir as duas partes - a escola e a família para chegar a uma solução... (Sujeito 4).

Fazemos um contato com a escola sim; quando o problema torna-se mais grave, o setor psicossocial é acionado. Então, a assistente social vai até a esco- la ver o que tá acontecendo, fazer um contato com o professor... (Sujeito 8).

Esse desconhecimento do que acontece na escola faz com que muitos psicólogos desconsiderem a importância de um laudo psicológico no meio educacional, muitas vezes entendido como algo definitivo, que marca a vida escolar do aluno.

\section{Como avalia seu trabalho, em relação a esse tipo de demanda}

Nesse núcleo, é possível observar uma análise individual da atuação e das condições de trabalho que a instituição oferece aos usuários desse serviço. Assim, foram pontuados aspectos relativos à formação e aos atributos físicos do local.

Dentre os entrevistados, sete destacam as condições físicas do local como grande obstáculo nos atendimentos e no desenvolvimento das atividades relativas a essa demanda. Isso também foi observado durante as visitas.

Outro ponto relevante, citado por três entrevistados, refere-se à formação acadêmica, quando afirmam não ter tido um maior contato com esse tipo de demanda específica, durante a graduação. Esses tiveram apenas aulas teóricas e buscaram conhecer mais sobre o assunto durante a prática. "É bem complicado, primeiro na graduação só temos mais teoria, quase nada de prática..." (Sujeito 6).

Mesmo assim, seis entrevistados avaliam sua atuação de maneira positiva, quando abordam a importância da atuação do psicólogo nas referidas instituições e apontam para a necessidade de mais profissionais no serviço público. "É um trabalho importante, deveria ser dada mais importância ao psicólogo na educação, porque esse trabalho é fundamental... Mas deveriam existir mais psicólogos, pois a demanda é muito grande e poucos profissionais" (Sujeito 7).

Apenas um deles reconhece que sua atuação poderia ser melhor, se houvesse mais investimentos em infraestrutura e formação. Já outro afirma que a política institucional é um dos fatores que prejudica sua atuação, quando impõe um modelo de atuação e requer resultados quantitativos dos atendimentos, conforme o trecho a seguir: "... Aqui se prioriza a quantidade ao invés da qualidade, temos que atender a todos que chegam..." (Sujeito 6). 


\section{Considerações finais}

As questões discutidas a partir das afirmações dos participantes apontam resultados semelhantes aos encontrados na literatura sobre a atuação do psicólogo diante das dificuldades de aprendizagem das crianças. Assim, suas concepções orientam suas ações profissionais, visto que a maioria dos profissionais entrevistados mantêm uma visão clínica e estereotipada dessas questões, quando apontam simplesmente o aluno, a família e as condições socioeconômicas como causadores dessas dificuldades. Nesse sentido, a atuação deles refere-se a uma análise superficial dos casos, encaminhamentos, terapia individual ou grupal e uma orientação aos pais.

Assim, os resultados demonstram a necessidade de se reavaliar do papel do psicólogo que atua com crianças com alguma queixa escolar. Ele deve incluir, em sua investigação, mais elementos, dentre eles, a análise e a intervenção na instituição escolar. É preciso que essa análise envolva mais encontros, não se limitando à identificação dos problemas, mas também na criação de estratégias com os pais e a escola, a fim de recuperar esse diálogo e, assim, sejam superadas as supostas dificuldades.

Constatou-se que todos os profissionais entrevistados estão insatisfeitos quanto ao local de trabalho, e isso é algo que também influencia a qualidade do serviço prestado, já que grande parte dos locais visitados não dispõe de material lúdico e educativo, não possui uma sala adequada que forneça o mínimo de privacidade. Desse modo, torna-se quase impossível estabelecer um diálogo eficaz com a criança e seus responsáveis.

A formação do psicólogo deve ser revista, porquanto até hoje é caracterizada por um modelo clínico, que, na prática, pode representar um campo distinto da educação, porém contempla ações e demandas semelhantes. Conforme abordagem realizada nessa pesquisa, instituições de saúde, educação e assistência social recebem diariamente essa demanda, qualificada como própria da psicologia escolar/educacional.

A reflexão sobre a necessidade de reorientar a formação dos psicólogos é pertinente, sendo recomendável um desenvolvimento que contemple o diálogo entre saúde e educação, ainda durante o processo acadêmico, pois essa diferenciação "imposta" não está presente no cotidiano da maioria das pessoas que buscam qualquer tipo de atendimento.
Outro fator relevante observado diz respeito à ausência de falas que contemplem a necessidade de atuação do psicólogo escolar/educacional no ambiente escolar. Todos afirmam que não há recursos humanos suficientes para a demanda existente nas instituições onde eles desempenham suas atividades, contudo nenhum afirma que isso poderia ser solucionado com a presença efetiva de psicólogos nas escolas.

Isso reflete o quanto estão "acostumados" a receber essa demanda que, na verdade, seria mais bem assistida no ambiente educacional, visto que o psicólogo nesse espaço estabeleceria ações não apenas investigativas (que buscam a causa do problema), mas teria respaldo para intervir, com o intuito de promover ações articuladas com os atores envolvidos.

Sabe-se que existem diferenças nas representações sociais entre os psicólogos que atuam no serviço público e os que atendem em consultórios particulares. Consequentemente, este estudo pode ser tomado como base ou incentivo a novas pesquisas que busquem analisar tais diferenças e, também, aprofundar essas discussões.

\section{Referências}

Andrada, E. G. C. (2005). Novos Paradigmas na Prática do Psicólogo Escolar. Psicologia: Reflexão e Crítica, 18(2), 196-199. doi:10.1590/S0102-79722005000200007.

Azevedo, A. C. P. (2000). Psicologia escolar: O desafio do estágio. Lorena, SP: Stiliano. doi:10.1590/ S0103-65642007000400003.

Braga, S. G., \& Morais, M. L. S. (2007). Queixa escolar: Atuação do psicólogo e interfaces com a educação. Revista Psicologia USP, 4, 35-51.

Braunstein, V. C. (2010). Um atendimento em orientação à queixa escolar numa perspectiva winnicottiana: Muito além do indivíduo. In Souza, B. P. (Org.). Orientação à queixa escolar. (pp. 59-78). São Paulo: Casa do Psicólogo.

Cabral, E., \& Sawaya, S. M. (2001). Concepções e atuação profissional diante das queixas escolares: Os psicólogos nos serviços públicos de saúde. Estudos Psicologia, 6(2), 143-155. doi:10.1590/ S1413-294X2001000200003. 
Carvalho, M. P. (2003). Sucesso e fracasso escolar: Uma questão de gênero. Educação e Pesquisa, 29(1), 185193. doi:10.1590/S1517-97022003000100013.

Collares, C. A. L., \& Moysés, M. A. (1994). A transformação do espaço pedagógico em espaço clínico - A patologização da educação. (Série Idéias, 23, pp. 25-31). São Paulo: FDE.

Machado, A. M., \& Souza, M. P. R. (Org.). (1997). Psicologia escolar: Em busca de novos rumos. São Paulo: Casa do Psicólogo.

Molina. R. C. M., \& Del Prette, Z.A. P. (2006). Funcionalidade da relação entre habilidades sociais e dificuldades de aprendizagem. Psico-USF, 11(1), 53-63.

Nakamura, M. S., Lima, V. A. A., Tada, I. N. C., \& Junqueira, M. H. R. (2008). Desvendando a queixa escolar: Um estudo no Serviço de Psicologia da Universidade Federal de Rondônia. Revista Semestral da Associação Brasileira de Psicologia Escolar e Educacional (ABRAPEE), 12(2), 423-429.

Patto, M. H. S. (1990). A produção do fracasso escolar: Histórias de submissão e rebeldia. São Paulo: T. A. Queiroz.
Patto, M. H. S. (1997). O papel social e a formação do psicólogo: Contribuição para um debate necessário. In M. H. S. Patto (Org.). Introdução à Psicologia escolar. (pp. 459-468). São Paulo: Casa do Psicólogo.

Santos, L. A. R. (2002). O psicólogo e sua prática na escola pública. Apontamentos para uma reflexão sobre a criticidade, a ousadia e a angústia. Psicologia Ciência e profissão, 22(3), 2-7.

Saraiva, L. F. O. (2007). Olhares em foco: Tensionando silenciamentos. In B. P. Souza (Org.). Orientação à queixa escolar. (pp. 59-78). São Paulo: Casa do Psicólogo.

Sawaya, S. M. (2000). Alfabetização e fracasso escolar; problematizando alguns pressupostos da concepção construtivista. Educação e Pesquisa, 26(1), 67-81. doi:10.1590/S1517-97022000000100005.

Souza, M. P. R. (2007). Prontuários revelando os bastidores: Do atendimento psicológico à queixa escolar. In B. P. Souza (Org.). Orientação à queixa escolar. (pp. 25-27). São Paulo: Casa do Psicólogo. 